\title{
Health Care Violence and Abuse towards Nurses in Hospitals in North of Iran
}

\author{
Mohammad Khademloo ${ }^{1}$, Fatemeh Sheikh Moonesi ${ }^{2} \&$ Hamed Gholizade ${ }^{1}$ \\ ${ }^{1}$ Department of Community Medicine, Mazandaran University of Medical Sciences, Sari, Iran \\ ${ }^{2}$ Department of Psychiatry, Psychiatry and behavioral Sciences Research Center, Mazandaran University of \\ Medical Sciences, Sari, Iran \\ Correspondence: Dr Fatemeh Sheikh Moonesi, Department of Psychiatry, Zareh Hospital, Sari, Mazandaran, \\ Iran. E-mail: fmoonesi@mazums.ac.ir
}

Received: March 6, 2013 Accepted: March 31, 2013 Online Published: May 20, 2013

doi:10.5539/gjhs.v5n4p211 URL: http://dx.doi.org/10.5539/gjhs.v5n4p211

The authors have disclosed no conflict of interest

\begin{abstract}
Aim: In the current survey, we explored the prevalence of verbal and physical abuse against the nurses in different hospitals of north of Iran. Methods: We performed a cross-sectional survey. Nurses were interviewed using a standardized questionnaire (Staff Observation Scale Revised (SOAS-R)). The sample covered 400 participants from 5 hospitals of Mazandaran University of medical sciences, Sari, Iran. Results: The sampling size involved 271 participants (271 forms from 400 forms (sampling population) were filled completely) including 193 female (71.2\%) and 78 male (28.8\%) participants. 79 (29.1\%) participants experienced physical abuse and 260 (95.9\%) participants were abused verbally. It was noted that in 35 cases $(44.3 \%)$ the patients were the source of physical abuse and in 44 cases $(55.6 \%)$ the members of patients' family were the source. In 79 (30.3\%) cases the patients were the source of verbal violence and in $139(53.4 \%)$ cases the members of patients' family were the source and in $42(16.1 \%)$ cases coworkers were the sources. Conclusion: Verbal abuse was a common type of violence in our study in north of Iran. There is a requirement to increase awareness about this significant problem among health care workers.
\end{abstract}

Keywords: violence, verbal, physical

\section{Introduction}

In recent years, job associated-violence was a complex and dangerous problem for the staffs (Beech et al., 2006; Cooper et al., 2002). Among different works, health care staffs were defined as one of the most groups that experience aggression (Bourn, 2003; Chappell et al., 2006; Wells et al., 2002; Çelik et al., 2012; Alencar et al., 2012).

Based on Nova Scotia Association of Health Organizations, violence is defined as any behavior which cause damage whether real or perceived. Researches revealed that the most frequent origin of abuse were patients, patients' family, visitors, doctors, other healthcare staffs and even nurse co-workers (May et al., 2002; Oweis et al., 2005; Uzun et al., 2003).

Among the hospitals workers nurses confront with verbal, emotional, physical and sexual abuse (Uzun et al., 2003; Gerberich et al., 2005). Due to Their presence in stressful conditions including accidents, deaths, staying to visit a doctor, or transfer of patients to a ward predispose the nurses to more abuse from patients or their companions than other hospital staffs (Islam, 2003). The impact of abuse on nurses result in tiredness, sleeping disorders, nightmares, stress, continuous headaches, chronic aches, spasm, diminished self esteem, self dissatisfaction, disappointment, short-temperedness, symptoms of amnesia (after being hit), phobia, depression, alcohol intake, smoking, and sometimes suicide. Physical violence will cause physical disorders including backache, or even the death of a nurse (Anderson, 2002; Gates et al., 1999; Lee et al., 1999; Nolan et al., 2001; Pejic, 2005; Rippon et al., 2000). 
There are different reports about the prevalence of abuse rate against nurses from $37 \%$ to $72 \%$ (Lin et al., 2005; Stirling et al., 2001).

Therefore in this study, we investigate the prevalence of verbal and physical abuse against the nurses in different hospitals of north of Iran which were related to Mazandaran University of Medical Sciences, Sari, Iran.

\section{Methods and Material}

\subsection{Subjects and Data Collection}

In this investigation, 400 nurses who were members of the Mazandaran University of Medical Sciences, sari, Iran took part as participants.

Questionnaires, along with approval forms, were sent to 400 nurses who were members of the university in various hospitals in charge of the Nursing Association. Nurses were informed that they could give back the forms to the head of the Nursing Association in related hospitals.

Exclusion criteria included who were mentally ill, and nurses with less than 1 year of job experience.

\subsection{Participants Recruitment}

The study included permanent staff who working continuously in the same post for at least one year. The questionnaires were distributed in informative sessions performed with groups of between 20 and 30 participants, who were informed with information about the research and details of how to response and hand in the study.

\subsection{Survey Data (Questionnaire)}

The experience with violence and aggressive behavior and the interactions performed for controlling such conditions were recorded by Staff Observation Scale Revised (SOAS-R) by Nijman and colleagues (Nijman et al., 1999) which was developed by researchers.

Characteristics of this questionnaire are its comprehensibility, and the psychometric feature. The questionnaire consists of 20 questions from three blocks of topics. The first block includes questions about the participant and their profession, like gender and age, the health care setting in which they work, their qualifications and experience at job.

In the second section, staff experience with violence and aggressive conditions is being evaluated. First participants are questioned separately about physically and verbally aggressive behavior: "Have you experienced physically aggressive behavior in the last twelve months?" and "Have you experienced verbal aggression in the last twelve months?". More questions refer to the kind and purpose of the aggressive behavior. The last part of questionnaire includes the need for procedures to manage violence and aggression. This part contains questions about physical and emotional consequences, general stress associated with the incidents, help which is provided in the hospital and their utilization and social support.

\subsection{Statistical Analysis}

Data was collected, reviewed, coded and entered into the computer program. Data was presented in the form of frequencies and percentages. Chi-squared test was used for comparing qualitative data. Statistical analysis was done using the SPSS program version 16 (SPSS Ver 16).

\subsection{Ethical Issues}

All personal data of the participants were secret and no one has access to them except researchers.

\section{Results}

While 354 questionnaires were received, just 271 could be analyzed and interpreted because the rest were not filled in completely. The study population involved 271 participants with mean \pm SD age of $36.8 \pm 9.35$ including 193 female (71.2\%) subjects with mean \pm SD age of $33.4 \pm 7.85$ and 78 male $(28.8 \%)$ participants with mean \pm SD age of $38.36 \pm 11.78$. More than two-thirds (76\%) were married at the time of survey, and 17.3 percent were single and the remaining $6.7 \%$ were separated/widow/divorced. The workplace of these people included emergency department 33 cases $(12.2 \%)$, internal department 44 cases $(16.2 \%)$, surgery department 46 cases $(16.9 \%)$, gynecology department 10 cases $(3.7 \%)$, psychology department 24 cases $(8.9 \%)$, operating room 32 cases $(11.8 \%)$, pediatrics department 17 cases $(16.3 \%)$ and other department 65 cases (24\%) (Table 1). 
Table 1. Characteristics of study population

\begin{tabular}{lll}
\hline Age & Number & Percent \% \\
$18-30$ & 94 & 34.6 \\
$31-43$ & 155 & 57.1 \\
$44-58$ & 22 & 8.1 \\
\hline Years of Work & & \\
$1-10$ & 182 & 67.1 \\
$11-21$ & 77 & 28.4 \\
$22-35$ & 12 & 4.4 \\
\hline Clinical Setting & & \\
Emergency Department & 33 & 12.2 \\
Internal Department & 44 & 16.2 \\
Surgery Department & 46 & 16.9 \\
Gynecology Department & 10 & 3.7 \\
Psychology Department & 24 & 8.9 \\
Operating Room & 32 & 11.8 \\
Pediatrics Department & 17 & 16.3 \\
Other Department & 65 & 24 \\
\hline Marital Status & & \\
Single & 47 & 17.3 \\
Married & 206 & 76 \\
Divorced/Widow/Separate (Reference) & 18 & 6.7 \\
\hline & & \\
\hline
\end{tabular}

79 (29.1\%) participants including 31 male and 48 female answered yes to this question "Have you experienced physically aggressive behavior in the last twelve months?". There were significant association between sex and answer of this question ( $\mathrm{p}=0.035)$. In 35 cases $(44.3 \%)$ the patients were the source of physical violence and in 44 cases $(55.6 \%)$ the members of patients' family were the source (Table 2). Unfortunately, threatening the nurses with physical harm was frequent behavior. Even if the rates were small, it is sad to confront that some of these threats are real.

$260(95.9 \%)$ participants answered yes to this question "Have you experienced verbal aggression in the last twelve months?". 185 of the victims were female and 75 were male. There was significant association between sex and answer of this question ( $\mathrm{p}=0.013)$. In 79 cases $(30.3 \%)$ the patients were the source of verbal violence and in 139 cases (53.4\%) the members of patients' family were the source and in 42 cases (16.1\%) coworkers were the source (Table 2).

Table 2. Source of violence against the nurses in this series

\begin{tabular}{lll}
\hline Identity of Perpetrator & Verbal Abuse (N=260) & Physical Violence (N=79) \\
\hline Member(S) of Patient's Family or Friends & $139(53.4 \%)$ & $44(55.6 \%)$ \\
Patient & $79(30.3 \%)$ & $35(44.3 \%)$ \\
Supervisor, Coworker, Doctor & $42(16.1 \%)$ & 0 \\
\hline
\end{tabular}




\section{Discussion}

In this study, we investigated the prevalence of verbal and physical violence against the nurses in different ward of the university hospitals. The main research questions in the present literature were: "Have you experienced physically aggressive behavior in the last twelve months?" and "Have you experienced verbal aggression in the last twelve months?"

The main outcomes of this survey demonstrated that verbal violence was a prominent professional risk for health care professions. On average, $95.9 \%$ of the participants have experienced verbal abuse and $29.1 \%$ have experienced physical violence.

In a study, Shoghi et al. (2008) reported that Verbal abuse was noted by $87.4 \%$ of the nurses during a 6 -month period, and physical violence by $27.6 \%$ during the same period. The majority of nurses reported that abuse was followed by either inaction or by actions which failed to satisfy the victim. Based on their results, men were exposed to more abuse than women. In contrast with our study, women exposed to more abuse.

Çelik et al. (2007) reported the prevalence of verbal and physical violence against nurses $91.1 \%$ and $33.0 \%$ respectively. Coworkers were indicated to be the most important source of verbally abusive behaviors while patients and patients' families were the important sources of physical violence. But in the present survey member(s) of patient's family or friends were source of violence for both verbal and physical abuse.

Franz et al. (2010) studied the prevalence of violence which happened during one year in 123 nurses and health care employees in a cross-sectional survey. They reported during the previous twelve months $70.7 \%$ of the participants experienced physical and $89.4 \%$ verbal aggression. Abbas et al (2010) revealed $27.7 \%$ of nurses in their study experienced abuse of any kind, $69.5 \%$ verbal abuse; and $9.3 \%$ physical abuse. Males were more exposed to violence during the period of 12 months than females. They concluded Workplace violence against nurses is an important issue in Egypt. Likewise with our research majority of the nurses experienced violence during past 12 month.

All of these studies like our current survey revealed that the prevalence of verbal abuse is more common in hospitals than physical abuse. In this regard, some organizational procedures, like waiting for long time and difficult connections between professionals and patients/visitors, will make the patients and their family unstable and therefore increase the likelihood of violence (Hinson et al., 2003). Enough management procedures are required to improve such conditions (Chappell et al., 2006). Interactions that patient or visitors endure frustrating experiences also result in violence in general hospitals and health care centers. Examples involve the procedures which cause pain and/or anxiety and procedures that provoke the patient to feel as he or she does not receive treatment seriously (Winstanley, 2005). The patient's health state may cause violent incidents. For instance, patients with cognitive problems cannot find the conditions adequately. This indicates that some violence is more frequent in special wards.

\section{Conclusion}

As noted above, these conditions need specific interventions and the temporal resources of staff (Winstanley, 2004). There is a requirement to increase awareness about this significant problem among health care workers beside the general public.

\section{Acknowledgments}

This research was the subject of the Doctorate of Medicine thesis of Hamed Gholizade as a student at Mazandaran University of Medical Sciences. It was supported by a grant of the Mazandaran University of Medical Sciences, Sari, Iran.

\section{References}

Anderson, C. (2002). Workplace violence: Are some nurses more vulnerable? Issues in Mental Health Nursing, 23, 351-366. http://dx.doi.org/10.1080/01612840290052569

Beech, B., \& Leather, P. (2006).Workplace violence in the health care sector: A review of staff training and integration of training evaluation models. Aggression and Violent Behaviour, 11, 27-43. http://dx.doi.org/10.1016/j.avb.2005.05.004

Bourn, J. (2003). A safer place to work: Protecting NHS hospital and ambulance staff from violence and aggression. London: The National Audit Office.

Celik, S. S., Celik, Y., Ağirbaş, I., \& Uğurluoğlu, O. (2007). Verbal and physical abuse against nurses in Turkey. International Nursing Review, 54, 359-366. http://dx.doi.org/10.1111/j.1466-7657.2007.00548.x 
Çelik, S., Çil, A., Yavaşçi, H., Gürbüz, S., Aslangiray, S., \& Somunoğlu, S. (2012). Violence against Nurses in Working Hours in Turkey. Int J Med Invest, 1(2), 28-43.

Chappell, D., \& Di Martino, V. (2006). Violence at work (3rd ed.). Geneva: International Labour Office.

Chappell, D., \& Di Martino, V. (2006). Violence at work (3rd ed.). Geneva: International Labour Office.

Cooper, C. L., \& Swanson, N. (2002). University of Manchester, Institute of Science and Technology, United Kingdom \& National Institute of Occupational Safety and Health, United States.

De Alencar, R. B., Gonçalves, B. B., Neto, M. L. R., \& Feitosa, U. N. S. (2012). Domestic Violence and the Experience of Health Services. Int J Med Invest, 1(2), 7-13.

Franz, S., Zeh, A., Schablon, A., Kuhnert, S., \& Nienhaus, A. (2010). Aggression and violence against health care workers in Germany - a cross sectional retrospective survey. BMC Health Services Research, 10, 51. http://dx.doi.org/10.1186/1472-6963-10-51

Gates, D. M., Fitzwater, E., \& Mayer, U. (1999).Violence against caregivers in nursing homes: Expected, tolerated, and accepted. Journal of Gerontological Nursing, 25, 12-22.

Gerberich, S. G., Church, T. R., McGovern, P. M., Hansen, H., Nachreiner, N. M., Geisser, M. S., ... Jurek, A. (2005). Risk factors for work-related assaults on nurses. Epidemiology, 16, 704-709. http://dx.doi.org/10.1097/01.ede.0000164556.14509.a3

Hinson, J., \& Shapiro, M. (2003). Violence in the workplace: Awareness and prevention. Australian Health Review, 26(1), 84-91. http://dx.doi.org/10.1071/AH030084

Islam, S. S., Edla, S. R., Mujuru, P., Doyle, E. J., \& Ducatman, A. M. (2003). Risk factors for physical assault. Statemanaged workers' compensation experience. American Journal of Preventive Medicine, 25, 31-37. http://dx.doi.org/10.1016/S0749-3797(03)00095-3

Kwak, R. P., Law,Y. K., Li, K. E., Ng, Y. C., Cheung, M. H., Fung, V. K., ... Leung, W. C. (2006). Prevalence of workplace violence against nurses in Hong Kong. Hong Kong Medical Journal, 12, 6-9.

Lee, S. S., Gerberich, S. G., Waller, L. A., Anderson, A., \& McGovern, P. (1999). Work-related assault injuries among nurses. Epidemiology, 10, 685-691. http://dx.doi.org/10.1097/00001648-199911000-00007

Lin, Y., \& Liu, H. (2005). The impact of workplace violence on nurses in South Taiwan. International Journal of Nursing Studies, 42, 773-778. http://dx.doi.org/10.1016/j.ijnurstu.2004.11.010

May, D. D., \& Grubbs, L. M. (2002). The extent, nature, and precipitating factors of nurse assault among three groups of registered nurses in a regional medical center. Journal of Emergency Nursing, 28(1), 11-17. http://dx.doi.org/10.1067/men.2002.121835.

Moustafa A.F. Abbas, Lamiaa A. Fiala, Amira GE. Abdel Rahman, Ayman E. Fahim. Epidemiology of Workplace Violence against Nursing Staff in Ismailia Governorate, Egypt. $J$ Egypt Public Health Assoc, 85(1 \& 2), 2010.

Nijman, H., Muris, P., Merckelbach, H., Palmstierna, T., Wistedt, B., Vos, A., ... Allertz, W. (1999). The Staff Observation Aggression Scale - Revised (SOAS-R). Aggress Beh, 25, 197-209. http://dx.doi.org/10.1002/(SICI)1098-2337(1999)25:3<197::AID-AB4>3.0.CO;2-C

Nolan, P., Soares, J., Dallendre, J., Thomson, S., \& Arnetz, B. (2001). Comparative study of the experiences of violence of English and Swedish mental health nurses. International Journal of Nursing Studies, 38, 419-426. http://dx.doi.org/10.1016/S0020-7489(00)00089-4

Oweis, A., \& Diabat, K. M. (2005). Jordanian nurses perception of physicians' verbal abuse: findings from a questionnaire survey. International Journal of Nursing Studies, 42, 881-888. http://dx.doi.org/10.1016/j.jinurstu.2004.11.005

Pejic, A. R. (2005). Verbal abuse: A problem for pediatric nurses. Pediatric Nursing, 31, 271-279.

Rippon, T. J. (2000). Aggression and violence in health care professions. Journal of Advanced Nursing, 31, 452-460. http://dx.doi.org/10.1046/j.1365-2648.2000.01284.x

Shoghi, M., Sanjari, M., Shirazi, F., Heidari, S., Salemi, S., \& Mirzabeigi, G. (2008). Workplace Violence and Abuse against Nurses in Hospitals in Iran. Asian Nursing Research, 2(3), 184-193. http://dx.doi.org/10.1016/S1976-1317(08)60042-0

SPSS Inc. (2007). SPSS Ver 16: Statistical Package for Social Studies, Release 16.0.0. Chicago, IL, USA. 
Stirling, G., Higgins, J. E., \& Cooke, M. W. (2001). Violence in A\&E departments: a systematic review of the literature. Accident and Emergency Nursing, 9, 77-85. http://dx.doi.org/10.1054/aaen.2000.0204

Uzun, O. (2003). Perception and experiences of nurses in Turkey about verbal abuse in clinical settings. Journal of Nursing Scholarship, 35(1), 81-85. http://dx.doi.org/10.1111/j.1547-5069.2003.00081.x

Wells, J., \& Bowers, L. (2002). How prevalent is violence towards nurses working in general hospitals in the UK? Journal of Advanced Nursing, 39(3), 230-240. http://dx.doi.org/10.1016/j.avb.2005.05.004

Winstanley, S. (2005). Cognitive model of patient aggression towards health care staff: The patient's perspective. Work \& Stress, 19(4), 340-350. http://dx.doi.org/10.1080/02678370500409747

Winstanley, S., \& Whittington, R. (2004). Aggressive encounters between patients and general hospital staff: Staff perceptions of the context and assailants' levels of cognitive processing. Aggressive Behavior, 30, 534-543. http://dx.doi.org/10.1002/ab.20052 